\title{
Solution for Injection in Administration System
}

National Cancer Institute

\section{Source}

National Cancer Institute. Solution for Injection in Administration System. NCI Thesaurus.

Code C149913.

Medicinal product consisting of a solution for injection presented in an administration system. 